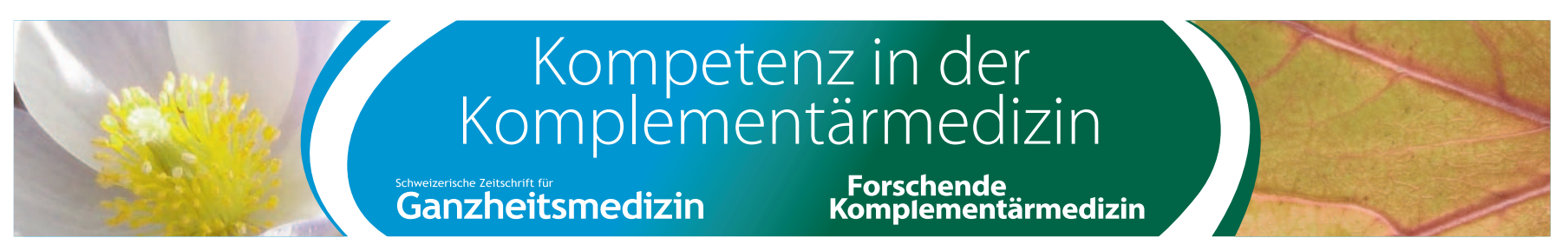

\begin{tabular}{|l|}
\hline \\
Fachseminar in klassischer Homöopathie \\
SHI Homöopathie Schule , CH-6300 Zug \\
Do 13. - Sa 15. September 2012 \\
\hline Scheue Kinder (Sil - Sanic - Calc-p) \\
Ohrenschmerzen - Intensivseminar mit \\
Mohinder Singh Jus, Martine Cachin Jus, \\
Stefan Bauer und Gabriela Keller \\
\hline SHI Homöopathie Schule•CH-6300 Zug \\
Tel 041 74821 77• schule@shi.ch• www.shi.ch \\
\hline
\end{tabular}

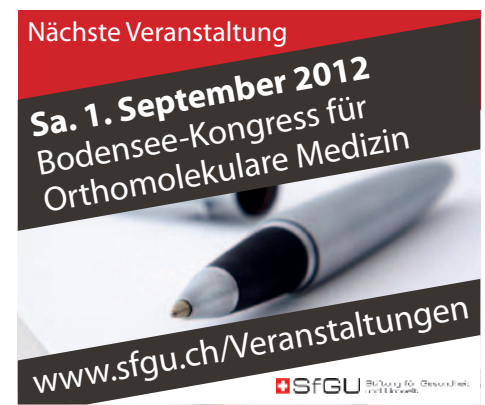

Das klassische chinesische Grundlagenwerk Huang-Di Nei-Jing Ling-Shu 黃帝內經靈樞

Vorläufer einer modernen wissenschaftlichen Heilkunde

Vier Wochenend-Seminare

LIFU INTERNATIONAL COLLEGE OF

CHINESE MEDICINE (LICCM)

Basel

\title{
Vorläufiges Programm
}

2./3. Juni 2012

Medizinisch-wissenschaftliche Grundlagen des Lingshu Jing

7./8. Juli 2012

Originale Chinesische Medizin

ohne «Meridiane», «Punkte» und «Energie»

1./2. September 2012

Grundlagen einer wissenschaftlichen Individual-Medizin

13./14. Oktober 2012

Moderne ärztliche Fachgebiete im Lingshu Jing

Anmeldung: Tel. +41613125585

(begrenzte Teilnehmerzah!!)

\section{KARGER}

Hier könnte Ihr Fort- und Weiterbildungsangebot stehen!

Nutzen Sie SCHWEIZERISCHE ZEITSCHRIFT FÜR GANZHEITSMEDIZIN zur effektiven Kommunikation mit Ihrer Zielgruppe! So schaffen Sie die besten Voraussetzungen sowohl gedruckt als auch online gesucht und gefunden zu werden.

Informationen und Angebote bei: Stefan Diekmann

Tel. +49 761 45207-13

s.diekmann@karger.de 